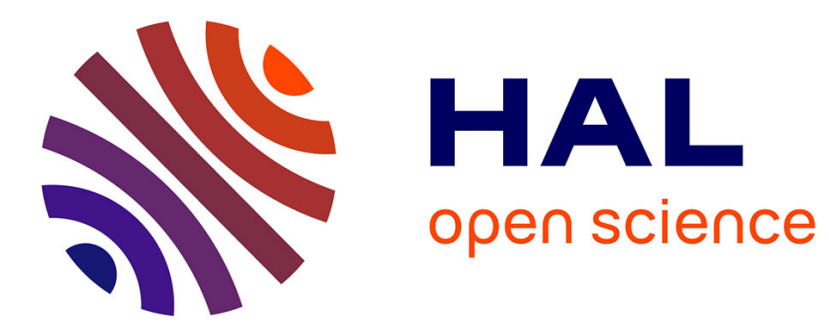

\title{
Morphological drivers of trophic cascades
}

Clémentine Renneville, Arnaud Le Rouzic, Michel Baylac, Alexis Millot, Stéphane Loisel, Eric Edeline

\section{To cite this version:}

Clémentine Renneville, Arnaud Le Rouzic, Michel Baylac, Alexis Millot, Stéphane Loisel, et al.. Morphological drivers of trophic cascades. Oikos, 2015, 125 (8), pp.1193-1202. 10.1111/oik.02877 . hal-01261837

\section{HAL Id: hal-01261837 https://hal.sorbonne-universite.fr/hal-01261837}

Submitted on 27 Jan 2016

HAL is a multi-disciplinary open access archive for the deposit and dissemination of scientific research documents, whether they are published or not. The documents may come from teaching and research institutions in France or abroad, or from public or private research centers.
L'archive ouverte pluridisciplinaire HAL, est destinée au dépôt et à la diffusion de documents scientifiques de niveau recherche, publiés ou non, émanant des établissements d'enseignement et de recherche français ou étrangers, des laboratoires publics ou privés. 


\title{
Morphological drivers of trophic cascades
}

\author{
Clémentine Renneville, Arnaud Le Rouzic, Michel Baylac, Alexis Millot, Stéphane Loisel \\ and Eric Edeline
}

\begin{abstract}
C. Renneville (clementine.renneville@etu.upmc.fr) and S. Loisel, CNRS/Sorbonne Universités/UPMC Univ Paris 06/INRA/IRD/Paris Diderot Univ. Paris 07/UPEC/Inst. d'Ecologie et des Sciences de l'Environnement - Paris (iEES-Paris), 7 quai St Bernard, FR-75252 Paris, France. A. Le Rouzic, CNRS/Univ. Paris-Sud/IRD/Univ. Paris-Saclay/Evolution, Génomes, Comportement, Ecologie (EGCE), Avenue de la Terrasse, FR-91198 Gif-sur-Yvette, France. - M. Baylac, MNHN/CNRS/UPMC Univ. Paris 06/EPHE/Inst. de Systématique, Evolution, Biodiversité (ISYEB), 45 rue Buffon, FR-75005 Paris, France, and: MNHN/CNRS/Outils et Méthodes de la Systématique Integrative (OMSI), 45 rue Buffon, FR-75005 Paris, France. - A. Millot, ENS/CNRS/CEREEP Ecotron Île-de-France, 78 rue du Château, FR-77140 Saint Pierre-lèsNemours, France. - E. Edeline, Sorbonne Universités/UPMC Univ Paris 06/CNRS/INRA/IRD/Paris Diderot Univ Paris 07/UPEC/Inst. d'Ecologie et des Sciences de l'Environnement-Paris (iEES-Paris), 7 quai St Bernard, FR-75252 Paris, France.
\end{abstract}

\begin{abstract}
Worldwide, local anthropogenic extinctions have recently been reported to induce trophic cascades, defined as perturbations of top consumers that propagate along food chains down to primary producers. This focus on the effects of top-consumer extinction (i.e. of species presence) ignores potential cascading effects of the rapid morphological changes that may precede extinction. Here, we show in an experimental, three-level food chain including medaka fish, herbivorous zooplankton and unicellular algae that varying body length of a single fish from large $(36.3 \mathrm{~mm})$ to small $(11.5 \mathrm{~mm})$ induced a stronger trophic cascade than varying an average-sized $(23.8 \mathrm{~mm})$ fish from being present to absent. The strength of fish predation on zooplankton scaled quasi linearly (not with a power exponent) with fish body length and associated gape width, suggesting that the resultant trophic cascade was morphology (not metabolism)-dependent. The effect of fish body length was stronger on phyto- than on zooplankton, because large-sized fish had the unique ability to suppress large-sized herbivores, which in turn had high grazing capacities. Hence, our results show that consumer body size, by setting diet breadth, can both drive and magnify the strength of trophic cascades. In contrast, fish body shape had no significant effect on fish predatory performances when its allometric component (the effect of size on shape) was removed. In the wild, human-induced body downsizing of top consumers is widespread, and mitigating the resultant perturbations to ecosystem function and services will require a paradigm shift from preserving species presence towards preserving species size structure.
\end{abstract}

Biodiversity loss caused by human activities is not random, but mainly affects large vertebrates at the top of trophic networks (Duffy 2003). In the impacted populations, collapse is often preceded by rapid changes in phenotypic traits (Olsen et al. 2004, Palkovacs et al. 2012). Best documented is a rapid adaptive change towards smaller body sizes, as demonstrated in exploited populations of fish (Olsen et al. 2004, Edeline et al. 2007, Darimont et al. 2009), mammals (Coltman et al. 2003) and plants (Law and Salick 2005). At the ecosystem level, exploitation generates anthropogenic trophic cascades - ATCs - (Daskalov et al. 2007, Estes et al. 2011) which refer to indirect effects of perturbation to top consumers cascading along food chains down to primary producers (Carpenter and Kitchell 1993). In food chains with odd numbers of species (e.g. three-level food chains), top predators release primary producers from herbivore control, while in even food chains top predators favour the control of primary producers by herbivores (Oksanen et al. 1981).

Despite an early recognition of the importance of largesized herbivores to the very existence of trophic cascades in lakes (Carpenter and Kitchell 1993), trophic cascade ecology often remains centred around studying the effects of local top consumer extinction (i.e. presence versus absence), and ignores potential for trait-dependent effects (Bolker et al. 2003, Persson et al. 2003, Werner and Peacor 2003). For instance, ATCs remain generally ascribed to local extinctions of top consumers in all of the world major biomes (Estes et al. 2011). Similarly, experimental studies on trophic cascades almost exclusively vary presence versus absence of top predators (Hulot et al. 2014 but see Lazzaro et al. 2009), and ATCs in marine systems are ascribed to declining toppredator densities with no consideration for the role of size truncation resulting from size-biased mortality (Daskalov et al. 2007, Baum and Worm 2009, Estes et al. 2011).

However, traits are key drivers of predatory performances. In particular, metabolic rates scale with body mass to a power exponent such that attack rates increase and handling times decrease with an increasing body size, while in parallel gape width and diet breadth increase linearly (Peters 1983, Woodward et al. 2005, Barneche et al. 2014). Therefore, 
there is a high potential for anthropogenic body downsizing per se to lower the strength of predator-prey links and to drive size-dependent ATCs (Persson et al. 2003).

Accordingly, Shackell et al. (2010) recently showed that body-downsizing caused by commercial fishing in populations of predatory fish induced an ATC in the Northwest Atlantic, despite that the biomass of predators remained constant, i.e. despite that predator numbers actually increased. Given that metabolism, including feeding rate, scales with body mass to a power exponent lower than one (often with a 3/4 exponent, Peters 1983, Woodward et al. 2005, Barneche et al. 2014), increased numbers of smaller-sized predatory fish should result in an overall increased prey consumption (see Supplementary material Appendix 1 for a formal demonstration). In contrast, the observed trophic cascade in the northwest Atlantic shows a relaxed predation pressure from predatory fish (Shackell et al. 2010). Therefore, the ATC in northwest Atlantic was not density- or physiology (metabolism)-dependent, but was instead size (morphology)dependent. This important observation, made on a large natural system, urgently calls for an improved understanding of the mechanisms driving size-dependent trophic cascades, and for a quantification of the relative contributions of consumer presence versus body size to the strength of trophic cascades. Unravelling these mechanisms and quantifying these relative contributions in an experimental setting was the first aim of our study.

The second aim of our study was to disentangle the relative contributions of length, shape and allometry (shape explained by length) in driving the size-dependency of trophic cascades. Many fish species present distinct body shapes associated with distinct trophic specializations called pelagic (limnetic) versus benthic morphs in lacustrine habitats (Robinson and Wilson 1994). Human predators may induce changes in body shape and the trophic morphology of impacted populations, and thus potentially alter resource use and drive shape-mediated ATCs (Haas et al. 2010, Franssen 2011). For instance, in the guppy Poecilia reticulata presence of large-sized predators (mimicking guppy exploitation by humans) induces subtle evolutionary changes in food acquisition strategies towards reduced consumption of algae and detritus and increased consumption of invertebrates (Zandonà et al. 2011). These changes in prey selectivity seem correlated with changes in guppy head shape (Palkovacs et al. 2011). However, body shape is generally linked to body length through an allometric component (Gould 1966), and failure to account for this allometry may erroneously ascribe to shape effects that are in fact size-dependent. Here, we explicitly separate the allometric and non-allometric components of shape to study their relative effects on predatory performances.

Specifically, we used an experimental, three-level food chain in which we varied in parallel both presence and body size of medaka fish Oryzias latipes (the top predator), and measured the resultant cascading effects on its herbivorous zooplankton prey and on unicellular algae grazed by zooplankton. We found that fish body size, but not shape without allometric component, drove the strength of the trophic cascade by setting the strength of predation experienced by large-sized herbivore, which in turn were the most efficient grazers.

\section{Material and methods}

\section{Experimental fish}

Medaka is a small freshwater fish from southeast Asia. Its small size (25-35 $\mathrm{mm}$ as adult), extreme resistance to environmental changes (temperature and salinity) and to manipulations make medaka an ideal model organism in biology (Kinoshita et al. 2009, Kirchmaier et al. 2015). In the wild, medaka inhabit stagnant and relatively shallow water (e.g. rice fields and irrigation canals). It feeds preferably on zooplankton (cladocerans and copepods) but also on annelids, larvae of Dipterans and even on macroalgae (filamentous algae or Closterium sp.) and benthic detritus when no other food is available (Terao 1985). Recently, it was shown that medaka from different populations of the Nagano Prefecture in Japan exhibit covariation between predatory behaviour (tendency to feed on surface versus benthic food items) and body shape (Iguchi and Kitano 2008), and that predation efficiency of adult medaka (Standard body length measured from the snout to the base of the caudal fin - SL - ranging from 26 to $36 \mathrm{~mm}$ ) on Daphnia pulex may be dependent on Daphnia body size (Mano and Tanaka 2012). These studies suggest that medaka is a particularly good model predator to explore trait-dependent trophic interactions.

The medaka used for the present experiment (SL ranged from 11.5 to $36.3 \mathrm{~mm}$, mean $\pm \mathrm{SD}=23.8 \pm 7.5 \mathrm{~mm}$ ) descended from 100 wild medaka caught in Kiyoshu (Toyohashi, Aichi Prefecture, Japan) in 2011, and stocked in artificial, outdoor ponds at CEREEP Ecotron Île-de-France near Paris, France (<www.foljuif.ens.fr >). In the artificial ponds, medaka naturally feed on zooplankton and invertebrate communities and reproduce from May to August. Here, we used fish sampled from a pond in February, and acclimatized to laboratory conditions during one week prior to the experiments.

\section{Behavioural assays}

Experiments were conducted at $24 \pm 1{ }^{\circ} \mathrm{C}$ under artificial light conditions (12 h-light:12 h-dark cycle). We used 60 aquaria (vol=1 l) containing initially a two-level food chain with phytoplankton (Scenedesmus spp.) and herbivorous zooplankton sampled in a nearby natural pond $(95 \%$ Daphnia pulex - hereafter Daphnia - and 5\% cyclopoid copepods present in both nauplius and copepodite stages). We generated pairs of identical aquaria $(n=30$ pairs per experiment) using a plankton splitter, which separates a parent sample of live plankton in twin samples (see photography in Supplementary material Appendix 2 Fig. A1).

A pilot methodological experiment showed that the plankton splitter generated identical algal concentrations, Daphnia counts and copepod counts in the two aquaria of a given pair (see analyses in Supplementary material Appendix 2 and script in Appendix 9). Hence, by generating no withinpair (i.e. between-treatment) variance in counts but only between-pair (i.e. within-treatment or residual) variance, our splitting method was conservative regarding the mean estimate of treatment effect on counts, and could have only decreased (not increased) the ratio between explained deviance and residual deviance in our ANOVAs (i.e. no added risk of false positive in models $1-3$, Table 1 ). Note that 
Table 1. Summary of the statistical models used to test presence- versus size-dependent effect of medaka on the food chain. Coefficient values were estimated against the intercept reference levels that represent zooplankton counts (log scale) or phytoplankton concentration when fish was absent in experiment 1 (model 1-3), predation probability on the smallest size class of Daphnia by the smallest sized fish (logit scale, model 4), predation probability on nauplius larvae in experiment 1 (logit scale, model 5), or grazing probability on phytoplankton in experiment 1 when the smallest sized fish was present (logit scale, model 6). In model 3 and 6, main effects (a and b) are from a model without an interaction term (by definition, main effects are without the added effect of an interaction). Fish length unit is mm, Daphnia size class unit is $\mathrm{mm}^{2}$. (:) indicates interaction between two predictors. $\left(^{*}\right)$ indicates overdispersed models, (¥) indicates that model 3 included residual heteroskedasticity as an exponential function (varExp within the gls function of the nlme library, Pinheiro et al. 2012) of fitted values $v_{i}: \operatorname{var}\left(\epsilon_{i}\right)=\sigma^{2} \exp \left(2 \delta v_{i}\right)$ where $\epsilon_{i}=$ residuals and $\sigma^{2}=$ variance of the normally-distributed residuals, as estimated with no heteroskedastic structure (Pinheiro and Bates 2000)

\begin{tabular}{|c|c|c|c|c|c|c|c|c|c|}
\hline Model & Trophic level & Response & Distribution & Link & Predictors & $\begin{array}{c}\text { Coefficient } \\
\text { value }\end{array}$ & $\begin{array}{l}\text { Statistic } \\
\text { value }\end{array}$ & $\mathrm{p}$-value & Pseudo-R ${ }^{2}$ \\
\hline 1 & Zooplankton & $\begin{array}{l}\text { Daphnia count } \\
(\mathrm{n}=360)\end{array}$ & Poisson* & $\log$ & $\begin{array}{l}\text { intercept } \\
\text { experiment } 2 \\
\text { fish presence } \\
\text { Daphnia size class }\end{array}$ & $\begin{array}{r}3.80 \\
1.14 \\
-1.40 \\
-6.70\end{array}$ & $\begin{array}{l}\mathrm{t}=20.50 \\
\mathrm{~F}=38.04 \\
\mathrm{~F}=53.35 \\
\mathrm{~F}=58.14\end{array}$ & $\begin{array}{l}p<0.001 \\
p<0.001 \\
p<0.001 \\
p<0.001\end{array}$ & 0.44 \\
\hline 2 & Zooplankton & $\begin{array}{l}\text { copepods count } \\
(\mathrm{n}=240)\end{array}$ & Poisson* & $\log$ & $\begin{array}{l}\text { intercept } \\
\text { experiment } 2 \\
\text { fish presence }\end{array}$ & $\begin{array}{r}0.62 \\
2.06 \\
-1.26\end{array}$ & $\begin{array}{l}\mathrm{t}=3.84 \\
\mathrm{~F}=237.95 \\
\mathrm{~F}=115.38\end{array}$ & $\begin{array}{l}p<0.001 \\
p<0.001 \\
p<0.001\end{array}$ & 0.68 \\
\hline 3 & Phytoplankton & $\begin{array}{l}\text { phytoplankton } \\
\text { concentration } \\
(n=1,200)\end{array}$ & Gaussian $¥$ & identity & $\begin{array}{l}\text { intercept } \\
\text { experiment } 2 \text { (a) } \\
\text { fish presence (b) } \\
\text { a:b }\end{array}$ & $\begin{array}{r}75.67 \\
-70.77 \\
9.73 \\
-9.35\end{array}$ & $\begin{array}{l}t=72.00 \\
F=4631.00 \\
F=328.00 \\
F=18.00\end{array}$ & $\begin{array}{l}p<0.001 \\
p<0.001 \\
p<0.001 \\
p<0.001\end{array}$ & 0.80 \\
\hline 4 & Zooplankton & $\begin{array}{l}\text { predation probability } \\
\text { on Daphnia } \\
(\mathrm{n}=180)\end{array}$ & binomial* & logit & $\begin{array}{l}\text { intercept } \\
\text { fish length } \\
\text { Daphnia size class }\end{array}$ & $\begin{array}{r}-4.51 \\
0.30 \\
-11.75\end{array}$ & $\begin{aligned} t & =-11.74 \\
F & =379.99 \\
F & =32.90\end{aligned}$ & $\begin{array}{l}p<0.001 \\
p<0.001 \\
p<0.001\end{array}$ & 0.75 \\
\hline 5 & Zooplankton & $\begin{array}{l}\text { predation probability } \\
\text { on copepods } \\
(\mathrm{n}=120)\end{array}$ & binomial* & logit & $\begin{array}{l}\text { intercept } \\
\text { experiment } 2 \\
\text { copepodites stage }\end{array}$ & $\begin{array}{r}0.50 \\
0.98 \\
-0.63\end{array}$ & $\begin{array}{l}\mathrm{t}=1.11 \\
\mathrm{~F}=5.14 \\
\mathrm{~F}=4.38\end{array}$ & $\begin{array}{l}0.269 \\
0.020 \\
0.040\end{array}$ & 0.07 \\
\hline 6 & Phytoplankton & $\begin{array}{l}\text { grazing probability } \\
\text { on phytoplankton } \\
(n=600)\end{array}$ & binomial* & logit & $\begin{array}{l}\text { intercept } \\
\text { experiment } 2 \text { (a) } \\
\text { fish length (b) } \\
\text { a:b }\end{array}$ & $\begin{array}{r}-2.69 \\
1.60 \\
0.06 \\
0.05\end{array}$ & $\begin{array}{l}\mathrm{t}=-22.25 \\
\mathrm{~F}=489.60 \\
\mathrm{~F}=173.71 \\
\mathrm{~F}=12.73\end{array}$ & $\begin{array}{l}p<0.001 \\
p<0.001 \\
p<0.001 \\
p<0.001\end{array}$ & 0.50 \\
\hline
\end{tabular}

adding a fixed 'aquarium-pair' effect in models $1-3$ (Table 1) did change the number of degrees of freedom, but did not affect model estimates or p-values in the F-tests.

Although counts were homogeneously split by our method, we found that copepodites and Daphnia tended to be slightly but significantly larger in the left branch of the splitter (Supplementary material Appendix 2). Hence, we spread this bias among the fish-present and fish-absent food chains (see below for fish addition) by alternating the position of the fishless aquarium between the left and right branches of the splitter. Therefore this bias could have only added noise to the data without any directional effect.

After $24 \mathrm{~h}$ fasting, a single medaka was added in one aquarium of each aquarium pair ( $\mathrm{n}=30$ fish), thus generating a three-level food chain, and the fish was allowed to forage on zooplankton during $24 \mathrm{~h}$. Then, the fish was removed, anaesthetized with tricaine methanesulfonate $\left(3 \times 10^{-4} \mathrm{~g}^{-1}\right)$, photographed from lateral and dorsal views (for subsequent morphometric measurements), and released. Zooplankton in each aquarium was fixed in ethanol (96\%) for subsequent enumeration and size measurement using the ZooScan (Gorsky et al. 2010). This device takes a high-resolution picture of the zooplankton sample, extracts each particle using the Zooprocess V.7.091 software, measures each particle size, and assigns it to a taxonomic category based on a "learning set" provided by the user using the Plankton Identifier V.1.261 software. We further complemented this automatic sorting by a manual check. Zoopankton body length (longest axis) ranged from $2.0 \times 10^{-2}$ to $2.0 \mathrm{~mm}$ in Daphnia $\left(\right.$ median $\left.=2.4 \times 10^{-1}\right)$, from $5.7 \times 10^{-2}$ to $1.7 \times 10^{-1} \mathrm{~mm}$ in nauplius larvae $\left(\right.$ median $\left.=6.8 \times 10^{-2}\right)$, and from $1.1 \times 10^{-1}$ to $5.9 \times 10^{-1} \mathrm{~mm}$ in copepodites $\left(\right.$ median $\left.=1.2 \times 10^{-1}\right)$. In our analyses (below), we assigned Daphnia into three size classes based on the log of the scanned body surface area, which provided a more accurate proxy for body size than the longest axis (central values of size classes: $3.1 \times 10^{-1}$, $4.7 \times 10^{-2}$ and $\left.7.2 \times 10^{-3} \mathrm{~mm}^{2}\right)$. We assigned copepods into two stage classes (nauplius and copepodite stages, respective central values : $3.0 \times 10^{-3}$ and $7.2 \times 10^{-3} \mathrm{~mm}^{2}$ ).

We measured phytoplankton concentration (in $\mu \mathrm{g} \mathrm{l}^{-1}$ chlorophyll a) in each aquarium using a spectrofluorimetric probe BBE, which measures the fluorescence emitted by the chlorophyll pigment content in response to excitement by light emitted by diodes. We recorded 10 measurements for each sample.

This whole experiment including behavioural tests, plankton and fish morphometric measurements was repeated twice (hereafter experiment 1 or 2), yielding a total of 120 aquaria and 60 fish.

\section{Medaka morphometric measurements}

We measured each fish body length $(n=60$ SL measurements) to the nearest $10^{-1} \mathrm{~mm}$ using ImageJ V.1.49m software (Abràmoff et al. 2004).

In order to quantify medaka body shape (Adams et al. 2004), we placed both landmarks and semi-landmarks on each medaka picture (Mitteroecker and Gunz 2009). Landmarks are defined as fixed homologous points in terms of anatomical structures, and semi-landmarks are sliding points 
approximately placed onto medaka contour by the observer and which final position is determined by minimizing the Procrustes distance criterion (Bookstein 1996). We digitized 21 points (8 landmarks and 13 semi-landmarks) onto the dorsal head shape (see photography in Supplementary material Appendix 3 Fig. A2_A) and 19 points (11 landmarks and 8 semi-landmarks) onto the lateral body shape of medaka (Supplementary material Appendix 3 Fig. A2_B) using tpsDig2 V.2.16 software (Rohlf 2010). We used the "geomorph" library (Adams et al. 2004) in R V.3.1.0 software (<www.r-project.org >) to perform generalized Procrustes analysis - GPA - (gpagen function of 'geomorph' library) and to remove non-shape variation (the effects of rotation, translation and the isometric effects of size). The GPA superimposes all dot patterns and performs three operations: a centring configuration, a size normalization (scaling), and a rotation calculated in order to minimize the sum of squared deviations between the coordinates of a same point (Rohlf and Slice 1990). The GPA further provides a consensus (the average fish body shape), the centroid size of each individual (the size before scaling), and the Procrustes shape coordinates (containing information on the superposed body shape).

In a pilot methodological experiment, we showed that this method allowed us to accurately discriminate individual medaka according to their shape, and was thus robust to the noise introduced by the digitizing procedure (see analyses in Supplementary material Appendix 4 and scripts in Appendix 9 and 11).

\section{Statistical analyses}

\section{Presence - versus size-dependency of the trophic cascade}

We modelled the general effects of fish presence on zooplankton counts and on phytoplankton concentrations in analyses of variance, in which each observations were made at the level of each single aquarium (models $1-3$ in Table 1). Model 1 included 360 observations (120 aquaria $\times 3$ Daphnia size classes), model 2 included 240 observations (120 aquaria $\times 2$ copepod stage classes), and model 3 included 1200 observations (120 aquaria $\times 10$ repeated measurements).

In contrast, modelling the effect of medaka body size on predation or grazing probability required using binomial GLM regressions (models 5-6 in Table 1) in which an observation was provided by an aquarium pair $(\mathrm{n}=60$ aquarium pairs), and in which response was defined as:

$p_{z o o}=\frac{A_{z}-P_{z}}{A_{z}}$ or $p_{p h y t}=\frac{P_{p}-A_{p}}{P_{p}}$

Where $A_{z}=$ zooplankton count in a given size class (Daphnia, 60 aquarium pairs $\times 3$ sizes classes $=180$ observations) or development stage (copepods, 60 aquarium pairs $\times 2$ stage classes $=120$ observations) in the fish-absent aquarium of an aquarium pair, $A_{p}=$ phytoplankton concentration in the fish-absent aquarium of an aquarium pair (60 aquarium pairs $\times 10$ repeated measures $=600$ observations), $P_{z}$ and $P_{p}=$ same variables in the fish-present aquarium of an aquarium pair. Hence, $p_{z o o}=$ probability for zooplankton to be eaten by fish, $p_{p h y t}=$ probability for phytoplankton to be grazed by zooplankton when the fish is removed (i.e. in the fish-absent aquarium compared to the fish-present aquarium).
In addition to the effects of fish presence or body length on the food chain, we tested in our models for the effects of replicating the experiment (experiment 1 or 2), and of zooplankton size class (real scale, coded as a continuous variable) or development stage (nauplius larvae versus copepodite stage, coded as a categorical variable), alone or in interaction with fish presence or fish body length. Because predictors were different for Daphnia (body size class) and copepods (development stage), we analysed their response to predation in two separate models. In our models, we also tested the effect of fish body mass and found it to be a weaker predictor of medaka predation efficiency on Daphnia (6\% less deviance explained) than fish body length. Finally, we also found gape width to be a slightly better predictor of medaka predation efficiency on Daphnia (0.8\% more deviance explained) than fish body length. However, we chose to keep body length in our analyses because it is a more universal morphological metric.

In selecting our models, we kept or discarded each effect based on AIC change when the effect was removed from the model. Only changes larger than two points in AIC - or qAIC for overdispersed models (Bolker 2014a), - were considered (Burnham and Anderson 2002). If AIC or qAIC change was not significant, the effect was discarded to keep the most parsimonious model. The selected models are presented in Table 1. We computed goodness of fit of the selected models as the pseudo- $\mathrm{R}^{2}$ (Table 1), i.e. as the deviance ratio between the selected model and the null model which included an intercept as the only effect. All statistical analyses were performed in R 3.1.0 software (<www.r-project.org >) with the 'nlme' (restricted maximum likelihood; Pinheiro et al. 2012) and 'bbmle' (maximum likelihood; Bolker 2014b) libraries (see scripts in Supplementary material Appendix 5 and 10).

Zooplankton counts were overdispersed (median count $=3$, mean count $=23$ ), and we thus explored two different classes of overdispersed count models based on estimating a multiplicative dispersion parameter (quasipoisson in the $\mathrm{glm}$ function of $\mathrm{R}$ ) or on a negative binomial distribution (zero-inflated mixture models had convergence problems with the full set of predictors). We found the model selection procedure to yield similar results with both model classes, and we chose to keep the quasipoisson model for its wide use and its standard implementation in the glm function of R.

\section{Computation of effect sizes}

We compared the relative contributions of medaka presence $v s$. body length to the strength of the trophic cascade using effects sizes on zoo- and phytoplankton predation probability, computed from overdispersed binomial GLMs similar to models 4-6 (Table 1, see also script in Supplementary material Appendix 6).

We computed the effect size of fish presence as $\mu=$ mean probability for prey to be eaten, as predicted from an intercept-only GLM fitted to the data using maximum likelihood. This was technically equivalent to comparing the effect of a $0.0 \mathrm{~mm}$ fish (i.e. medaka absence) with the effect of a medium-sized ( $\mathrm{SL}=23.8 \mathrm{~mm}$ ) fish, and could be written as $\mu=\overline{P_{23.8}}-\overline{P_{0}}$, where $\overline{P_{23.8}}=$ mean probability for prey to be eaten when the fish was present, and $\overline{P_{o}}=$ mean probability for prey to be eaten when no fish was present. 
We computed the effect size of fish body length as $s=\overline{P_{36.3}}-\overline{P_{11.5}}$, where $\overline{P_{36.3}}=$ mean probability for prey to be eaten when the largest fish in the population $(\mathrm{SL}=36.3$ $\mathrm{mm}$ ) was present, and $\overline{P_{11.5}}=$ mean probability for prey to be eaten when the smallest fish in the population $(\mathrm{SL}=11.5$ $\mathrm{mm}$ ) was present. Both $\overline{P_{36.3}}$ and $\overline{P_{11.5}}$ were predicted from an overdispersed GLM fitted to the data by maximum likelihood, and which included an intercept plus fish body length as predictors. Thus, dividing $\mu$ by 23.8 and $s$ by $36.3-11.5=24.8$ would yield the slopes of the linear relationships between predation probability on plankton and medaka body length. We estimated mean and standard deviation for both $\mu$ and $s$ in a bootstrap procedure in which we randomly sampled half of the observations (with replacement), fitted the models and recorded parameters, repeated 1000 times.

Additionally, we complemented this bootstrap procedure by a Markov chain Monte Carlo (MCMC) approach in JAGS ver. 3.4 (Plummer 2003). Specifically, we fitted an overdispersed binomial model to each full count dataset (Daphnia, copepods and algae). Following Bayesian standards, we modelled overdispersion as an individualobservation random effect (Kéry 2010). The models included an intercept $\mu$ and a slope for the effect of medaka body length (standardized to 0 mean and unity standard deviation), from which we computed $s$ as defined above. Additionally, we computed the $\mu / s$ ratio as part of the MCMC chains.

We ran three independent chains of 50000 iterations each with a burn-in period of 40000 iterations. We thinned the three chains every 5 th iteration, yielding a posterior of 6000 samples for each parameter. Uninformative priors for regression parameters were defined as normal distributions with zero mean and 100 standard deviation, and for variance parameters as a uniform distribution between 0 and 10 . Convergence was assessed using the Gelman-Rubin statistic (Gelman and Rubin 1992). The MCMC p-value for the $\mu / s$ ratio was defined as twice the proportion of the posterior which was larger than one when the posterior mode was less than one, or as twice the proportion of the posterior which was less than one when the posterior mode was larger than one. This test was equivalent to a bilateral $t$-test in which $\mathrm{H}_{0}$ was $\mu=s$ and $\mathrm{H}_{1}$ was $\mu \neq s$. See script in Supplementary material Appendix 7 for more details about our MCMC approach.

\section{Links between medaka body shape and predatory performance}

We explored how medaka body shape, allometry-free shape (i.e. size-independent body shape), and allometric shape (i.e. size-dependent body shape) influenced predatory performance using partial least square regressions (two blocks partial least squares - 2B-PLS - Rohlf and Corti 2000). 2B-PLS (two.b.pls function of 'geomorph' library) diagonalizes one of the two matrices of covariance between the two data blocks and produces pairs of PLS orthogonal axes (PLS axes) that maximize the covariation between the two data blocks. The result of a 2B-PLS is thus similar to the output of a principal component analysis (redefinition of orthogonal axes in the multivariate morphological space), except that the PLS define morphological axes that are the most correlated to predation variables. In all three 2B-PLS regressions (Table 2, one 2B-PLS per fish view and one with the combined views), predation variables constituted the multivariate response, i.e. the five probabilities of zooplankton to be consumed by medaka (three Daphnia size classes + two copepod stages).

We extracted allometry-free and allometric shapes from multivariate analysis of variance (MANOVA, (Monteiro 1999); manova function of R) between body shape and logtransformed centroid size (Table 2, one MANOVA per fish view; We previously checked with a MANCOVA that fish body shape did not vary with experiment and/or sex. See script in Supplementary material Appendix 8). Residuals from the MANOVA provided allometry-free residuals that correspond to the size-independent body shape coordinates (i.e. allometry-free shape), while predicted shape values from the MANOVA provided the size-dependent body shape coordinates (i.e. allometric shape). We further computed the proportion of variance in shape explained by allometry as $A / B$, where $A=$ allometric shape variance, and $B=$ total shape variance, as predicted by the MANOVA.

Morphometric analyses were performed with the 'geomorph' library for R (Adams and Otárola-Castillo 2013), and allometric shape change were depicted using the tpsRegr V1.28 software (Rohlf 2003).

\section{Data deposition}

Data available from the Dryad Digital Repository: <http:// dx.doi.org/10.5061/dryad.6m1 m6> (Renneville et al. 2015).

Table 2. Summary of morphometric analyses. Correlations in 2B-PLS analyses (Cor values) are between the fish shape and predatory behaviour. Allometry-free shape are residuals from the regression of log-transformed centroid size on shape and allometric shape are the predicted values (see Methods for more details).

\begin{tabular}{|c|c|c|c|c|c|c|c|c|}
\hline \multirow{3}{*}{$\frac{\text { Analysis type }}{\text { MANOVA }}$} & \multirow{3}{*}{$\frac{\text { Response }}{\text { body shape }}$} & \multirow{3}{*}{$\begin{array}{c}\text { Predictors } \\
\text { transformed } \\
\text { entroid size }\end{array}$} & \multicolumn{6}{|c|}{ Fish view } \\
\hline & & & \multicolumn{2}{|c|}{ Lateral view } & \multicolumn{2}{|c|}{ Dorsal view } & \multicolumn{2}{|c|}{ Lateral + dorsal views } \\
\hline & & & Pillai $=0.95$ & $\mathrm{p}<0.001$ & Pillai $=0.89$ & $\mathrm{p}<0.001$ & & \\
\hline 2B-PLS shape & $\begin{array}{l}\text { zooplankton } \\
\text { proportions }\end{array}$ & body shape & Cor $=0.60$ & $\mathrm{p}<0.001$ & Cor $=0.69$ & $\mathrm{p}<0.001$ & Cor $=0.72$ & $\mathrm{p}<0.001$ \\
\hline $\begin{array}{l}\text { 2B-PLS allometry } \\
\text { free shape }\end{array}$ & $\begin{array}{l}\text { zooplankton } \\
\text { proportions }\end{array}$ & allometry free shape & Cor $=0.30$ & $p=0.894$ & Cor $=0.45$ & $p=0.297$ & Cor $=0.48$ & $p=0.498$ \\
\hline $\begin{array}{l}\text { 2B-PLS allometric } \\
\text { shape }\end{array}$ & $\begin{array}{l}\text { zooplankton } \\
\text { proportions }\end{array}$ & allometric shape & Cor $=0.77$ & $\mathrm{p}<0.001$ & Cor $=0.80$ & $p<0.001$ & Cor $=0.80$ & $\mathrm{p}<0.001$ \\
\hline
\end{tabular}




\section{Results}

\section{Presence - versus size-dependency of the trophic cascade}

\section{Presence-dependent effects}

Presence of an average fish significantly decreased zooplankton abundance (Table 1, model 1 and 2) and significantly increased phytoplankton concentration (Table 1, model 3), indicating that medaka induced a trophic cascade in our aquaria.

Small-sized Daphnia were significantly more numerous than large-sized Daphnia (Table 1, model 1), while there was no abundance difference between the two copepod development stages (Table 1, 'copepod stage' discarded from model 2). There was no significant interaction between medaka presence and Daphnia size class or copepod development stage (discarded from model 1 and 2), indicating that an average medaka had no significant foraging preference among zooplankton sizes or stages (but see size-dependent effects below).

The significant effect of experiment on zooplankton count and phytoplankton concentration (Table 1, model 1-3) shows that zooplankton was more abundant and phytoplankton less concentrated during the second experiment. Finally, we found a significant interaction between fish presence and experiment on phytoplankton concentration (Table 1, model 3), indicating that fish presence increased less sharply phytoplankton concentration during the second experiment.

\section{Size-dependent effects}

The probability for Daphnia to be eaten by medaka significantly increased with medaka body length (Table 1 , model 4; Fig. 1) and, in turn, the probability for phytoplankton to

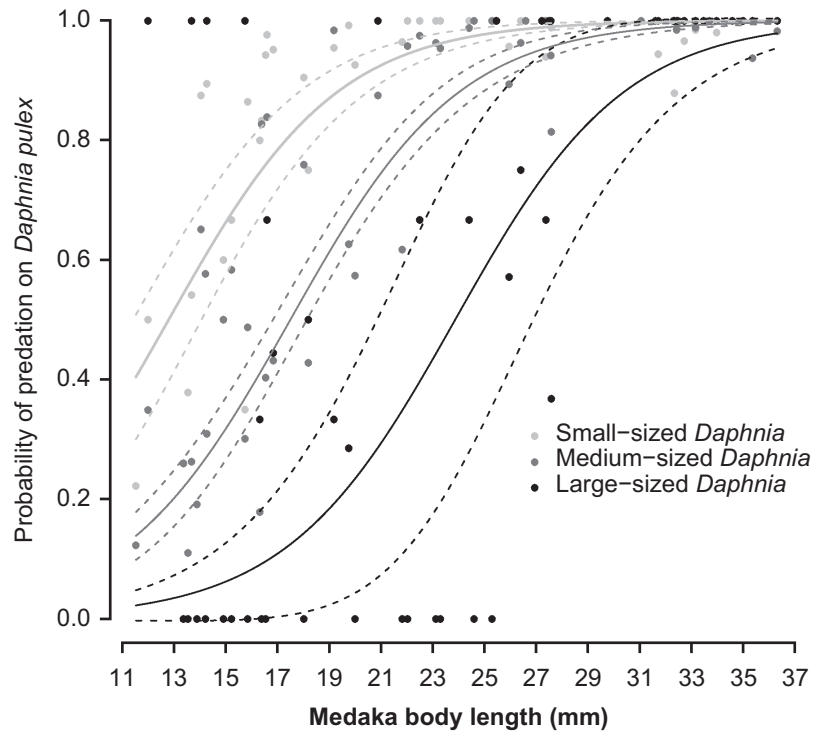

Figure 1. Size-dependent predation probability. Probability for Daphnia to be eaten by medaka as a function of medaka body length. Dots correspond to the raw data and lines correspond to model predictions with 95\% confidence intervals (as predicted from model 4, Table 1). be grazed by Daphnia significantly increased when a larger fish was removed (Table 1, model 6; Fig. 2). Therefore, medaka body length significantly influenced the strength of the trophic cascade induced by medaka. In contrast, medaka body length did not influence the probability for copepods (either copepodite or nauplius stage) to be eaten by medaka ('fish length' discarded from model 5 in Table 1), showing that the size-dependent trophic cascade was mediated by Daphnia only.

Small-sized Daphnia were significantly more consumed than large-sized Daphnia (Table 1, model 4), and the largest Daphnia were predated only by large medaka (Fig. 1). However, we did not find any significant interaction between Daphnia size and medaka length (discarded from model 4 in Table1; Fig. 1), indicating that small and large medaka had the same preferences in terms of prey size.

Finally, we found that the probability for phytoplankton to be grazed by zooplankton overall increased during the second experiment, as compared with the first experiment. This effect was due to higher zooplankton numbers during the second experiment.

\section{Comparison of effect sizes}

The bootstrap suggested that the effect of varying medaka presence on zooplankton was $95 \%$ of the effect of varying medaka body length (Fig. 3). Specifically, an average-sized medaka increased predation probability on Daphnia by $75 \%$ (mean $\pm 5.210^{-2} \mathrm{SD}$ ) compared to a fish-absent aquarium, while a large-sized medaka increased this probability by $79 \%$ (mean $\pm 5.810^{-2} \mathrm{SD}$ ) compared to a small-sized medaka. In line with the bootstrap procedure, the MCMC approach suggested that the effect size of varying medaka presence on Daphnia was $98 \%$ ( $\pm 1.410^{-4}$ SD) of the effect

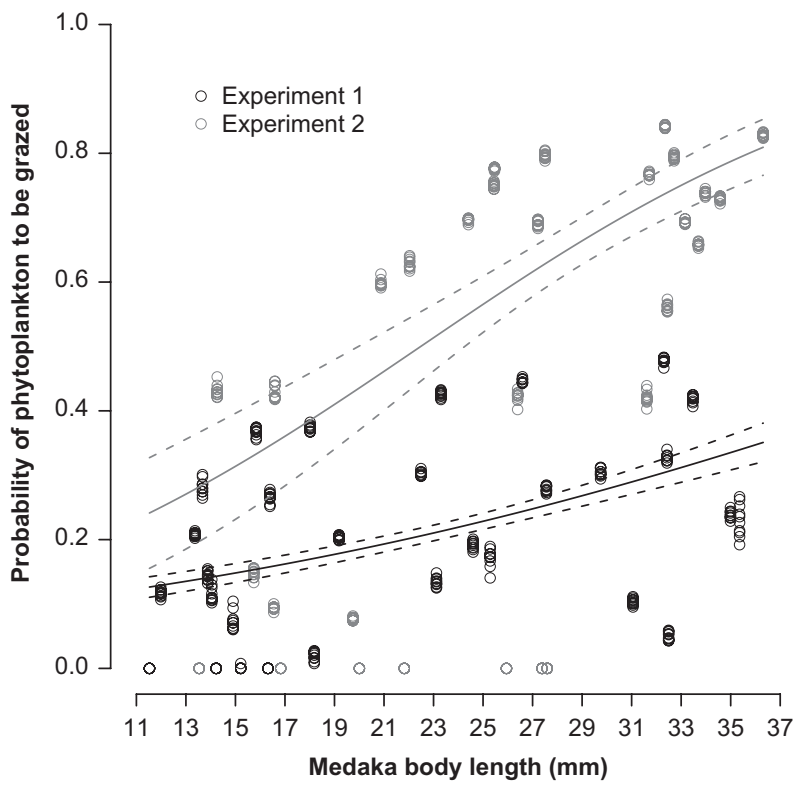

Figure 2. Size-dependent cascading effect. Probability for phytoplankton to be grazed by zooplankton when medaka is removed from an aquarium (i.e. change from fish presence to fish absence), as a function of medaka body length (see Methods for more details). Dots represent the raw data, and lines represent predictions with $95 \%$ confidence intervals (as predicted from model 6 , Table 1 ). 
Daphnia
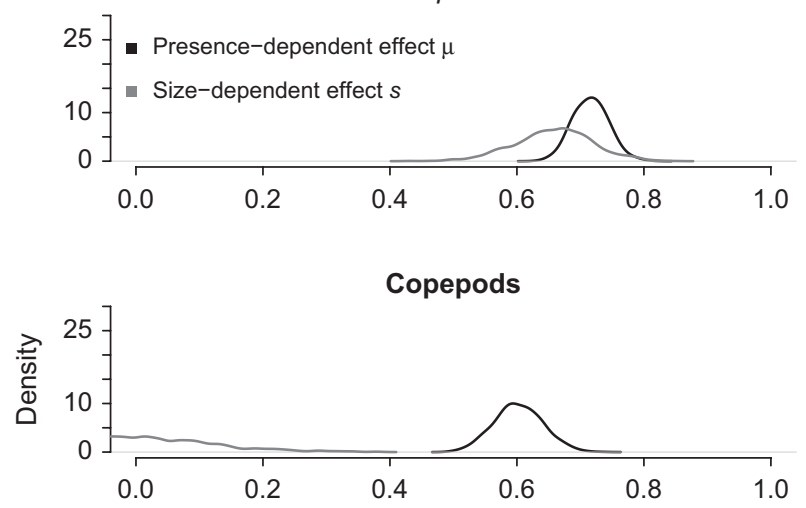

Phytoplankton

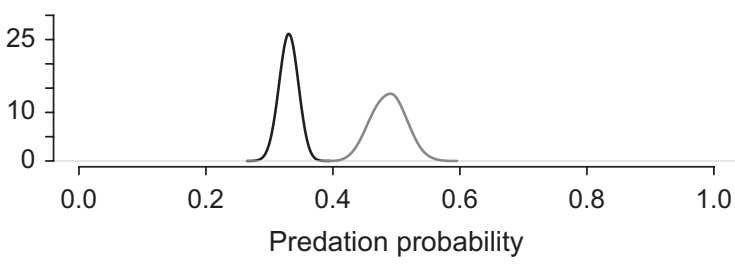

Figure 3. Density probability of effect sizes as estimated by bootstrap. The effect size of fish presence (presence-dependent effects $\mu$, black line) indicates the mean change in probability for being eaten or grazed when an average medaka was added in a fishless aquarium (Daphnia and copepods) or when the average medaka was removed and aquarium returned to a fishless state (phytoplankton). The effect size of fish body length (size-dependent effects $s$, grey line) indicates the mean change in probability for being eaten or grazed when medaka body length was changed from minimum to maximum (Daphnia and copepods) or from maximum to minimum (phytoplankton). Predation probabilities were estimated 1000 times in a bootstrap sampling procedure (see text for more details). Densities were estimated using a Gaussian smoothing kernel with a standard deviation of 0.01 .

of varying medaka body length. The MCMC p-value was 0.01 , indicating that this difference was significant.

In contrast, the effect of medaka on copepods was almost only presence-dependent (Fig. 3). Specifically, an averagesized medaka increased predation probability on copepods (of either stage) by $73 \%$ (mean $\pm 4.1 \quad 10^{-2} \mathrm{SD}$ ) compared to a fish-absent aquarium, while a large-sized medaka had almost no further effect $\left(\right.$ mean $\left.=0.04 \% \pm 1.210^{-1} \mathrm{SD}\right)$ compared to a small-sized medaka. The MCMC approach confirmed that the effect of medaka body length on copepod counts was not significantly different from 0 .

The effect of varying medaka presence on phytoplankton in the bootstrap was $77 \%$ of the effect of varying medaka body length (Fig. 3). Specifically, removal of an average-sized medaka increased grazing probability by $27 \%$ $\left(\right.$ mean $\left.\pm 1.0 \times 10^{-2} \mathrm{SD}\right)$ compared to a fish-absent aquarium, while removal of a large-sized medaka increased this probability by $35 \%$ (mean $\pm 2.8 \times 10^{-2} \mathrm{SD}$ ) compared to removal of a small-sized medaka. The MCMC approach suggested that the effect size of varying medaka presence was $38 \%( \pm 2.7$ $\times 10^{-2} \mathrm{SD}, \mathrm{MCMC} \mathrm{p}$-value $\left.<0.001\right)$ of the effect of varying medaka body length, i.e. suggested a stronger effect of sizedependency than the bootstrap procedure.

\section{Links between medaka body shape and predatory performance}

We found that the allometry explained $11 \%$ of variance in dorsal shape and $20 \%$ of variance in lateral shape. Allometric component visualization showed that large-sized medaka had a proportionally larger and more anterior mouth, a shorter skull and a stockier body than small-sized medaka (Fig. 4).

2B-PLS regressions showed a high correlation between body shape and fish predatory behaviour (Table 2, 2B-PLS shape), thus supporting results from the GLM-based analysis showing a significant effect of body length on medaka predatory performance and on the resultant strength of the trophic cascade (Table 1, model 4 and 6). However, we found no significant correlation between allometry-free shape and fish predatory performance (Table 2, 2B-PLS allometry-free shape), indicating that body shape after accounting for the allometric component did not significantly influence medaka predatory performances in our experiment. Accordingly, we logically found a significant effect of allometric shape on medaka predatory behaviour (Table 2, 2B-PLS allometric shape).

\section{Discussion}

As expected, we found that medaka presence induced a trophic cascade in which zooplankton was suppressed and unicellular algae were released from grazing by zooplankton. However, in contrast with the dominant focus on presencedependent trophic cascades, we found that the strength of this trophic cascade was more size- than presence-dependent.

In our experiments, the increase in predation probability on Daphnia induced by varying medaka body length from small to large was $105 \%$ of the increase induced by varying medaka from absent to present. This effect-size difference parallels body-length difference between medaka being large or small $(36.3-11.5=24.8 \mathrm{~mm})$ and medaka being present or absent $(23.8-0=23.8 \mathrm{~mm})$, since $24.8 / 23.8 \times 100$ $\approx 105 \%$. In other words, the slope of the relationship between predation strength and medaka body length was identical when varying independently body length from 0 to $23.8 \mathrm{~mm}$ or from 11.5 to $36.3 \mathrm{~mm}$. Therefore, medaka predation probability on Daphnia presumably scaled quasilinearly with medaka body length as would be expected from morphology-dependent feeding rates, and not with a power exponent as would be expected from metabolism-dependent feeding rates (Peters 1983, Barneche et al. 2014). This result is in line with the results of Shackell et al. (2010), who found in the northwest Atlantic that fishing-induced body downsizing of predatory fish drove a trophic cascade reflecting a relaxed strength of predation despite that their total number actually increased (see the introduction). Therefore, both experimental and empirical data point to morphological (but not metabolic) constraints on predator-prey interactions as prominent drivers of the strength of trophic cascades.

Linear size scaling of medaka predation strength on Daphnia was likely mediated by gape width and resultant diet breadth. Accordingly, diet breadth scales linearly with body size in both terrestrial (Sinclair et al. 2003) and aquatic habitats (Claessen et al. 2002, Woodward et al. 2005). 


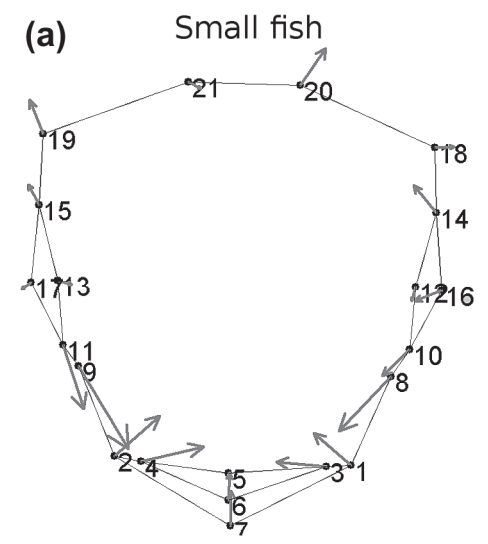

(b) Large fish

(c)

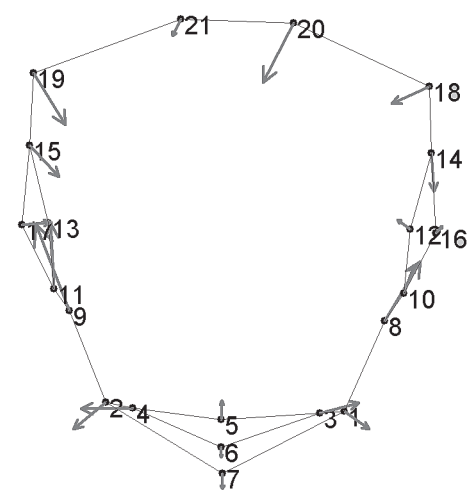

Small fish

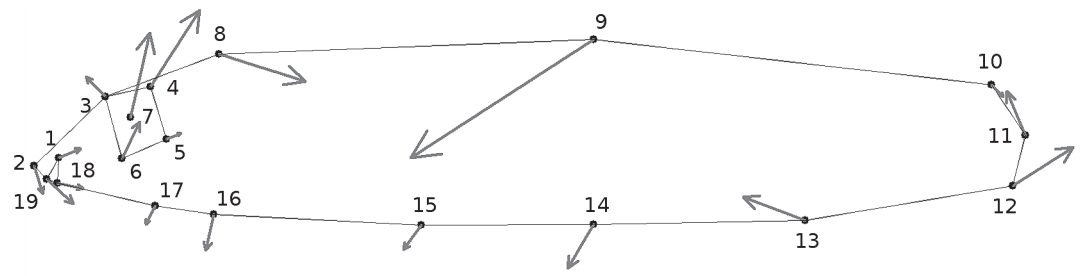

(d)

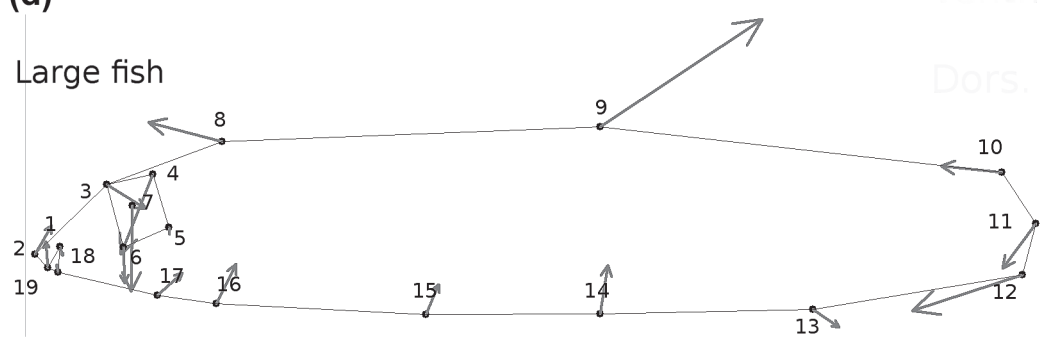

Figure 4. Medaka allometric shape. Shape variation between small and large medaka. The solid line represents the shape of an average fish. Vectors show the change from the average to the smallest specimen (a and c) and from the average to the largest specimen (c and d), for dorsal view (a and b; mouth down oriented; see also Supplementary material Appendix 3 Fig. A2) and lateral view (c and d; back down oriented; see also Supplementary material Appendix 3 Fig. A2). Differences (arrow length) are tenfold exaggerated to facilitate deformation visualization.

Hence, as medaka diet breadth was expanding in parallel with increasing medaka body length and gape width, a larger proportion of the Daphnia population became available for predation and the medaka-Daphnia predator-prey link was strengthening. Accordingly, gape width was a slightly better predictor than body length for medaka predation efficiency on large-sized Daphnia. In contrast, copepods, due to their small body size, were apparently included into the prey size range of both small and large medaka, such that the strength of the medaka-copepod, predator-prey link was not sizedependent. Therefore, our results, together with the study of Shackell et al. (2010), suggest that size-dependent diet breadth might play a central role in mediating the strength of predator-prey interactions, and from there in driving the strength of trophic cascades.

Importantly, comparison of effect sizes of medaka on zoo- and phytoplankton with both the bootstrap and MCMC approaches reveal that the contribution of sizedependency to the strength of the trophic cascade was magnified as the cascade was moving down along the food chain. This magnification apparently operated because large-sized medaka, in contrast with small and medium-sized medaka, were capable of preying upon large Daphnia (Fig. 1), which in turn have the highest filtering capacities (Burns 1969). This result is in line with theoretical models predicting that the strength of trophic cascades is stronger in presence of a small plant/herbivore body size ratio, such that large-sized herbivores are highly efficient grazers and potent magnifiers of the strength of trophic cascades (Shurin and Seabloom 2005, DeLong et al. 2015). Accordingly, herbivorous Daphnia are one or two orders of magnitude larger than their unicellular algal food and are, as also underscored by our results, potent magnifiers of the strength of trophic cascades (Carpenter and Kitchell 1993). In grasslands, large mammalian herbivores are also orders of magnitude larger than their plant food, and they have indeed been shown to be central for the control of plant biomass (Shurin and Seabloom 2005, Wilmers et al. 2006, Holdo et al. 2009). Hence, we believe that our experimental results are qualitatively valid for a wide range of ecosystems, i.e. that size-dependent trophic cascades and their potential magnification at the herbivore-plant interface should systematically be considered in freshwater, marine or terrestrial biomes.

Beyond body length, we also explored whether medaka body shape influenced predatory performances and drove a 
shape-mediated trophic cascade. We found that body shape including allometry was significantly linked with medaka predatory performances. However, body shape without its allometric component did not influence medaka predatory performances, highlighting the need to correctly account for the effect of body length on shape before testing for relationships between body shape and behaviour. This negative result in our experiment might be due to 1) an effective absence of any significant covariation between allometryfree shape and predatory behaviour at the within-population level, and/or 2) to the fact that we used only pelagic prey (plankton), while specialization in fish is often associated with the contrasted consumption of pelagic versus benthic prey (Robinson and Wilson 1994).

In human-perturbed ecosystems, the strength of ATCs is likely to be modulated by the amplitude of body downsizing experienced by top predators. The amplitude tested in our experiment (from 36.3 to $11.5 \mathrm{~mm}$ ) is modest compared to anthropogenic changes observed in the wild. For instance, in the western Scotian Shelf ecosystem (northwest Atlantic) where fishing induced an ATC, planktivorous fish shrank from ca 35 to $30 \mathrm{~cm}$, and benthivorous fish from ca 58 to $42 \mathrm{~cm}$ between 1970 and 2008 (Shackell et al. 2010). Often, however, body downsizing is more severe. In the southern Gulf of St Lawrence cod Gadus morhua mean length at maturity decreased from 65 to $40 \mathrm{~cm}$ in females and from 55 to $35 \mathrm{~cm}$ in males (Swain 2011). On longer time scales, decrease in mean body length may be even larger. Archaeological records of skeletal parts suggest that mean body length of cod in the Gulf of Maine (USA) has decreased from ca 100 to $30 \mathrm{~cm}$ due to overfishing (Jackson et al. 2001). In large part, such fishing-induced body downsizing reflects evolutionary changes (Coltman et al. 2003, Olsen et al. 2004, Edeline et al. 2007), and thus both trait change and resultant ATCs might be slow to reverse (Law 2000).

The size-dependency and potential poor reversibility of ATCs calls for a reassessment of conservation measures for biodiversity. Currently, management plans are focused on preserving minimum population numbers to avoid the negative effects of demographic stochasticity on population persistence, i.e. focus on preserving population presence. This classical conservationist perspective should be coupled with a preservation of population size structure, which would limit the strength of ATCs and maintain ecosystem functioning. Importantly, a functional, size-based management also meets conservationist objectives because large-sized individuals often have an increased fecundity and are thus more likely to contribute to increasing population numbers and to relaxing the effects of demographic stochasticity (Berkeley et al. 2004). Additionally, through their elevated egg production, large-sized females are also key to maintaining strong density-dependent regulation and dampen the effects of environmental stochasticity on population dynamics (Hidalgo et al. 2011, Botsford et al. 2014). Finally, preserving population size structure may protect from predator-prey reversals, in which anthropogenic body-downsizing results in downgraded trophic rank and increased predation mortality for the impacted population (Fauchald 2010). Taken together, these results suggest that integrating size-structure preservation into management plans would improve our ability to maintain biodiversity and restore ecosystems.
Acknowledgements - We thank Diego R. Barneche for insightful and fruitful comments on an earlier version of this manuscript. We are indebted to Prof. Kiyoshi Naruse (NIBB, Okazaki, Japan) for his support in capturing and transporting wild medaka from Japan to France, and for his advices for maintaining medaka at the CEREEP Ecotron Île-de-France. We are grateful to Gérard Lacroix for his many advices and for providing the zooplankton splitter, and also to Elisa Thébault for her suggestions. This work received financial support from Région Ile-De-France (R2DS PhD fellowship for $\mathrm{CR}$ ) and the French National Research Agency (project ANR-10CEPL-0010 PULSE) and from IDEX SUPER (project Convergences J14U257 MADREPOP). We declare that we have no competing interests.

\section{References}

Abràmoff, M. D. et al. 2004. Image processing with Image J. - Biophotonics Int. 11: 36-42.

Adams, D. C. and Otárola-Castillo, E. 2013. geomorph: an R package for the collection and analysis of geometric morphometric shape data. - Meth. Ecol. Evol. 4: 393-399.

Adams, D. C. et al. 2004. Geometric morphometrics: ten years of progress following the "revolution." - Ital. J. Zool. 71: 5-16.

Barneche, D. R. et al. 2014. Scaling metabolism from individuals to reef-fish communities at broad spatial scales. - Ecol. Lett. 17: $1067-1076$.

Baum, J. K. and Worm, B. 2009. Cascading top-down effects of changing oceanic predator abundances. - J. Anim. Ecol. 78: 699-714.

Berkeley, S. A. et al. 2004. Fisheries sustainability via protection of age structure and spatial distribution of fish populations. - Fisheries 29: 23-32.

Bolker, B. 2014a. Dealing with quasi-models in R. - In: R documentation, vignette for 'bbmle'package. $-<\mathrm{ftp}: / /$ mirrors.xmu. edu.cn/CRAN/web/packages/bbmle/vignettes/quasi.pdf $>$.

Bolker, B. 2014b. R development core team. Maximum likelihood estimation and analysis with the bbmle package. - < http:// CRAN.R-project.org/package=bbmle $>$.

Bolker, B. et al. 2003. Connecting theoretical and empirical studies of trait-mediated interactions. - Ecology 84: 1101-1114.

Bookstein, F. L. 1996. Landmark methods for forms without landmarks: morphometrics of group differences in outline shape. - Med. Image Anal. 1.

Botsford, L. W. et al. 2014. Cohort resonance: a significant component of fluctuations in recruitment, egg production, and catch of fished populations. - ICES J. Mar. Sci. 71: 2158-2170.

Burnham, K. P. and Anderson, D. R. 2002. Model selection and multimodel inference: a practical information-theoretic approach. - Springer.

Burns, C. W. 1969. Relation between filtering rate, temperature, and body size in four species of Daphnia. - Limnol. Oceanogr. 14: 693-700.

Carpenter, S. R. and Kitchell, J. F. 1993. The trophic cascade in lakes. - Cambridge Univ. Press.

Claessen, D. et al. 2002. The impact of size-dependent predation on population dynamics and individual life history. - Ecology 83: $1660-1675$.

Coltman, D. W. et al. 2003. Undesirable evolutionary consequences of trophy hunting. - Nature 426: 655-658.

Darimont, C. T. et al. 2009. Human predators outpace other agents of trait change in the wild. - Proc. Natl Acad. Sci. 106: 952-954.

Daskalov, G. M. et al. 2007. Trophic cascades triggered by overfishing reveal possible mechanisms of ecosystem regime shifts. - Proc. Natl Acad. Sci. USA 104: 10518-10523. 
DeLong, J. P. et al. 2015. The body size dependence of trophic cascades. - Am. Nat. 185: 354-366.

Duffy, J. E. 2003. Biodiversity loss, trophic skew and ecosystem functioning. - Ecol. Lett. 6: 680-687.

Edeline, E. et al. 2007. Trait changes in a harvested population are driven by a dynamic tug-of-war between natural and harvest selection. - Proc. Natl Acad. Sci. USA 104: 15799-15804.

Estes, J. A. et al. 2011. Trophic downgrading of planet earth. - Science 333: 301-306.

Fauchald, P. 2010. Predator-prey reversal: a possible mechanism for ecosystem hysteresis in the North Sea? - Ecology 91: 2191-2197.

Franssen, N. R. 2011. Anthropogenic habitat alteration induces rapid morphological divergence in a native stream fish. - Evol. Appl. 4: 791-804.

Gelman, A. and Rubin, D. B. 1992. Inference from iterative simulation using multiple sequences. - Stat. Sci. 7: 457-472.

Gorsky, G. et al. 2010. Digital zooplankton image analysis using the ZooScan integrated system. - J. Plankton Res. 32: 285-303.

Gould, S. J. 1966. Allometry and size in ontogeny and phylogeny. - Biol. Rev. 41: 587-638.

Haas, T. C. et al. 2010. Morphological responses of a stream fish to water impoundment. - Biol. Lett. 6: 803-806.

Hidalgo, M. et al. 2011. Synergistic effects of fishing-induced demographic changes and climate variation on fish population dynamics. - Mar. Ecol. Prog. Ser. 426: 1-12.

Holdo, R. M. et al. 2009. A disease-mediated trophic cascade in the Serengeti and its implications for ecosystem C. - PLoS Biol 7: e1000210.

Hulot, F. D. et al. 2014. Differential responses of size-based functional groups to bottom-up and top-down perturbations in pelagic food webs: a meta-analysis. - Oikos 123: 1291-1300.

Iguchi, K. and Kitano, S. 2008. Local specialists among endangered populations of medaka, Oryzias latipes, harboring in fragmented patches. - Environ. Biol. Fishes 81: 267-276.

Jackson, J. B. et al. 2001. Historical overfishing and the recent collapse of coastal ecosystems. - Science 293: 629-637.

Kéry, M. 2010. Introduction to WinBUGS for ecologists: Bayesian approach to regression, ANOVA, mixed models and related analyses. - Academic Press.

Kinoshita, M. et al. 2009. Medaka: biology, management and experimental protocols. - Wiley-Blackwell.

Kirchmaier, S. et al. 2015. The genomic and genetic toolbox of the teleost medaka (Oryzias latipes). - Genetics 199: 905-918.

Law, R. 2000. Fishing, selection, and phenotypic evolution. - ICES J. Mar. Sci. 57: 659-668.

Law, W. and Salick, J. 2005. Human-induced dwarfing of Himalayan snow lotus, Saussurea laniceps (Asteraceae). - Proc. Natl Acad. Sci. USA 102: 10218-10220.

Lazzaro, X. et al. 2009. Predator foraging behaviour drives foodweb topological structure. - J. Anim. Ecol. 78: 1307-1317.

Mano, H. and Tanaka, Y. 2012. Size specificity of predation by Japanese medaka Oryzias latipes on Daphnia pulex. - J. Freshwater Ecol. 27: 309-313.

Mitteroecker, P. and Gunz, P. 2009. Advances in geometric morphometrics. - Evol. Biol. 36: 235-247.

Monteiro, L. R. 1999. Multivariate regression models and geometric morphometrics: the search for causal factors in the analysis of shape. - Syst. Biol.: 192-199.

Oksanen, L. et al. 1981. Exploitation ecosystems in gradients of primary productivity. - Am. Nat. 118: 240-261.

Supplementary material (available online as Appendix oik02877 at <www.oikosjournal.org/appendix/oik-02788>). complementary analyses: Appendix 1-4. Scripts: Appendix $5-11$.
Olsen, E. M. et al. 2004. Maturation trends indicative of rapid evolution preceded the collapse of northern cod. - Nature 428: 932-935.

Palkovacs, E. P. et al. 2011. Eco-evolutionary trophic dynamics: loss of top predators drives trophic evolution and ecology of prey. - PLoS ONE 6: e18879.

Palkovacs, E. P. et al. 2012. Fates beyond traits: ecological consequences of human-induced trait change. - Evol. Appl. 5: 183-191.

Persson, L. et al. 2003. Gigantic cannibals driving a whole-lake trophic cascade. - Proc. Natl Acad. Sci. USA 100: 4035-4039.

Peters, R. H. 1983. The ecological implications of body size. - Cambridge University Press.

Pinheiro, J. C. and Bates, D. M. 2000. Mixed-effects models in S and S-PLUS. Statistic and computing collection. - Springer Press.

Pinheiro, J. et al. 2012. nlme: linear and nonlinear mixed effects models. <http://CRAN.R-project.org/package $=$ nlme $>$.

Plummer, M. 2003. JAGS: program for analysis of Bayesian graphical models using Gibbs sampling. - Proc. 3rd Int. Workshop Distrib. Stat. Comput. 124: 125.

Renneville, C. et al. 2015. Data from: Morphological drivers of trophic cascades. - Dryad Digital Repository, <http://dx.doi. org/10.5061/dryad.6m1m6>.

Robinson, B. W. and Wilson, D. S. 1994. Character release and displacement in fishes: a neglected literature. - Am. Nat. 144: 596-627.

Rohlf, F. J. 2003. tpsRegr: multivariate regressions. - Dept of Ecology and Evolution. <http://life.bio.sunysb.edu/morph/ soft-tps.html>.

Rohlf, F. J. 2010. tpsDig: digitize landmarks and outline. - Dept of Ecology and Evolution. < http://life.bio.sunysb.edu/morph/ soft-tps.html>.

Rohlf, F. J. and Slice, D. 1990. Extensions of the Procrustes method for the optimal superimposition of landmarks. - Syst. Biol. 39: 40-59.

Rohlf, F. J. and Corti, M. 2000. Use of two-block partial least-squares to study covariation in shape. - Syst. Biol. 49: 740-753.

Shackell, N. L. et al. 2010. Decline in top predator body size and changing climate alter trophic structure in an oceanic ecosystem. - Proc. R. Soc. B 277: 1353-1360.

Shurin, J. B. and Seabloom, E. W. 2005. The strength of trophic cascades across ecosystems: predictions from allometry and energetics. - J. Anim. Ecol. 74: 1029-1038.

Sinclair, A. R. E. et al. 2003. Patterns of predation in a diverse predator-prey system. - Nature 425: 288-290.

Swain, D. P. 2011. Life-history evolution and elevated natural mortality in a population of Atlantic cod (Gadus morhua). - Evol. Appl. 4: 18-29.

Terao, O. 1985. Contribution to the study of the ecology of the medaka (Oryzias latipes), under natural conditions: life span, reproduction, food habits and its seasonal changes. - Ms thesis of Tokyo University.

Werner, E. E. and Peacor, S. D. 2003. A review of trait-mediated indirect interactions in ecological communities. - Ecology 84: 1083-1100.

Wilmers, C. C. et al. 2006. Predator disease out-break modulates top-down, bottom-up and climatic effects on herbivore population dynamics. - Ecol. Lett. 9: 383-389.

Woodward, G. et al. 2005. Body size in ecological networks. - Trends Ecol. Evol. 20: 402-409.

Zandonà, E. et al. 2011. Diet quality and prey selectivity correlate with life histories and predation regime in Trinidadian guppies. - Funct. Ecol. 25: 964-973. 